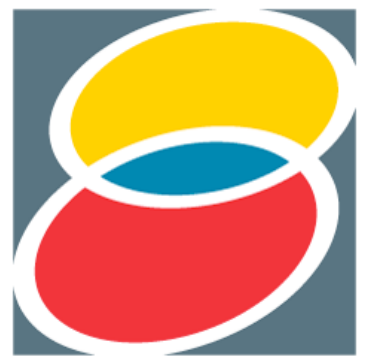

\title{
$8^{\circ}$ Congresso de extensão \\ universitária da UNESP
}

\section{TERAPIA ASSISTIDA POR CÃES NA APRENDIZAGEM DE ADOLESCENTES COM DEFICIÊNCIA INTELECTUAL}

\author{
Thais Oliveira Bunduki, Simone Ghedini Costa Milanez, UNESP - FFC, Campus: \\ Marília, Terapia Ocupacional, e-mail: thaisbunduki@hotmail.com, Bolsa de \\ Iniciação Científica, CNPQ.
}

\section{Eixo: "Direitos, Responsabilidades e Expressões para o Exercício da Cidadania"}

Resumo: A realização deste projeto justifica-se pelo fato da Terapia Assistida por Cães na educação de adolescentes com deficiência intelectual nas escolas ser um tema de extrema relevância. Este projeto tem por objetivo avaliar a eficácia do uso da terapia assistida por cães, analisando os benefícios da presença do animal durante as atividades desenvolvidas por eles. Este é um estudo comparativo, no qual um adolescente participou das atividades assistidas pelo cachorro e o outro não. Os dados relativos aos atendimentos mediados pela Terapia Assistida por Cães revelaram que seu uso é muito benéfico, uma vez que promove motivação ao assistido e aumenta o vínculo entre o terapeuta e o paciente.

Palavras Chave: Terapia Assistida por Cães, Deficiência Intelectual, Educação Especial.

\section{Introdução}

A realização deste projeto justifica-se pelo fato da Terapia Assistida por Cães na educação de adolescentes com deficiência intelectual nas escolas ser um tema de extrema relevância, entretanto, ainda com muito poucos estudos científicos no Brasil.

Estudos realizados por Flôres (2009) apontam que são inúmeros os benefícios físicos, mentais, sociais e emocionais que os animais podem proporcionar tanto em

\begin{abstract}
The realization of this project is justified by the fact of Dogs Assisted Therapy in the education of adolescents with intellectual disabilities in schools is a very important topic. This project aims to assess the efficacy of assisted therapy dogs, analyzing the benefits of the animal's presence during the activities developed by them. This is a comparative study, in which a teenager participated in the activities assisted by the dog and the other does not. Data on consultations mediated Dogs Assisted Therapy revealed that its use is very beneficial as it promotes motivation to assisted and increases the bond between the therapist and the patient.
\end{abstract}

Keywords: Dogs Assisted Therapy, Intellectual Disabilities, Special Education.

terapias como, simplesmente, no convívio diário. Bem estar, afastamento do estado da dor, encorajamento das funções da fala e das funções físicas, redução da pressão sanguínea e freqüência cardíaca, estímulos a memória e cognição, diversão e diminuição do isolamento, oportunidade de comunicação e convivência, possibilidade de troca de informações e de ser ouvido, sentimento de segurança, socialização e motivação, diminuição da ansiedade, relaxamento e alegria, aumento da confiança em si próprio e do grupo e diminuição do estresse. 
Segundo Capote e Costa (2011) a Terapia assistida por Animais é realizada por profissionais da área da saúde e é documentada e avaliada de forma a desenvolver e melhorar os funcionamentos físico, social, emocional e cognitivo das pessoas envolvidas no processo. Apresenta objetivos claros e dirigidos, com critérios estabelecidos, sendo 0 animal parte integral do processo de tratamento.

Para Ferreira (2012), embora a TAA traga benefícios em qualquer fase da vida do ser humano, ela é especiamente indicada para crianças, pois elas estabelecem com os cães uma comunicação recíproca que possibilita o desenvolvimento da autoestima, respeito e companheirismo.

Uma das características dos cães que favorecem o vínculo com o ser humano é a interação social e uso de mecanismos de comunicação. Dessa forma, a espécie canina e o ser humano se desenvolvem na interação com demais componentes de seu meio ambiente social. Assim, o cão adquiriu um importante papel na sociedade contemporânea, sendo foco de fortes vínculos afetivos (ALTHAUSEN, 2006, p.17).

Visto que a terapia com animais tem grande potencial terapêutico, profissionais da saúde e da educação passam a utilizar - animal como recurso auxiliar no desenvolvimento afetivo, social e cognitivo das pessoas (CAETANO, 2010).

Os estudos de Leal e Natalie (2007) consideram que as intervenções que se ocupam da participação de animais possuem objetivos diretos de promover atividades que contribuam para a saúde e o bem-estar das pessoas tanto com função motivacional, educacional, lúdica ou terapêutica, assim como o de melhorar o funcionamento físico, social, emocional e cognitivo, numa perspectiva biopsicossocial.

"A interação entre crianças e animais é inata, pois não exige uma interação verbal, os gestos, a curiosidade de um sobre o outro, o afago, enfim, o contato de um com o outro tem um significado além das palavras" (DOTTI, 2005).

\section{Objetivos}

Este projeto tem por objetivo avaliar a eficácia do uso da terapia assistida por cães no processo de aprendizagem de adolescentes com deficiência intelectual, analisando os benefícios da presença do animal durante as atividades desenvolvidas por eles.

\section{Material e Métodos}

\section{Participantes}

Participaram deste estudo dois adolescentes com idade de 17 e 18 anos, sendo um do gênero feminino que será referida como $\mathrm{E}$ e um do gênero masculino que será referido como G. Ambos frequentam o ensino médio de uma escola estadual do município de Marília, SP. Os critérios estabelecidos para a seleção dos participantes foram: a) diagnóstico de deficiência intelectual; b) nível escolar semelhante; c) não apresentação de medo de animais.

Este é um estudo comparativo, no qual um adolescente participou das atividades assistidas pelo cachorro e o outro não. Os dois alunos estavam na mesma classe. Os responsáveis pelos alunos selecionados foram informados sobre a pesquisa $e$ assinaram o Termo de Consentimento Livre e Esclarecido, no qual foram informados sobre o objetivo da pesquisa, a realização das terapias assistidas, da presença do animal durante a realização das mesmas e da posterior divulgação dos resultados obtidos com a pesquisa.

\section{Animal}

O animal participante foi um cão manso de porte médio, de aproximadamente 10 anos de idade, macho, de raça não definida, vacinado e que estava sob controle periódico pelo médico veterinário da ONG responsável. Durante a realização das sessões de terapia assisitda, o cão apresentava boa saúde. Em todos os atendimentos, o cão foi usado como referência e como exemplicação dos assuntos trabalhados.

Local

A pesquisa foi realizada na Sala de 
Recursos Multifuncionais da Escola Estadual Dr. Waldemar Moniz Da Rocha Barros, localizada no município de Marília SP.

\section{Instrumentos}

Para a coleta de dados durante as sessões de Terapia Assistida por Cães foram utilizados os seguintes instrumentos:

a) Avaliação com a utilização do Plano de Desenvolvimento Individual (POKER et al., 2013) com o objetivo de investigar o nível de aprendizagem dos alunos.

b) Diário de campo: ao término de cada sessão, foram anotados em um caderno os detalhes da intervenção no que diz respeito à relação do aluno com o cachorro, resposta às atividades solicitadas, dificuldades encontradas pelo aluno, entre outros.

\section{Procedimentos}

1 a etapa - Foi realizada análise dos prontuários dos alunos com deficiência intelectual indicados pela diretora da escola, a fim de conhecer os alunos e coletar o maior número de informações possíveis sobre eles. A partir dessa análise dos prontuários, foram escolhidos os possíveis participantes e solicitadas à professora da Sala de Recursos Multifuncionais as últimas avaliações deles, com intuito de se verificar o nível de aprendizagem dos mesmos e escolher aqueles com níveis de aprendizagem semelhantes. Com base na análise, foram selecionados dois alunos com diagnóstico fechado de deficiência intelectual, um dos quais participou das sessões de Terapia Assistida por Cães e o outro que realizou as mesmas atividades sem a presença do cão.

2 ${ }^{\mathbf{a}}$ etapa - Realização da avaliação dos alunos por meio do preenchimento pela professora da Sala de Recursos Multifuncionais do Plano de Desenvolvimento Individual (PDI) (POKER et al, 2013), para verificação da aprendizagem dos alunos.

3 etapa - Realização das sessões de Terapia Assistida por Cães para E., enquanto $\mathrm{G}$. realizou as mesmas atividades sem o cão. Após a identificação das principais áreas de dificuldades dos alunos, foram propostas dez sessões de atendimento terapêutico ocupacional para cada um dos alunos. Nas sessões de terapia assistida foram trabalhados conteúdos específicos nos quais os alunos apresentaram maior dificuldade, entre eles: atenção, memória, linguagem e raciocínio lógico. Também foram trabalhadas questões relacionadas à vida diária e à realidade dos alunos, como por exemplo: autocuidado, sexualidade e uso de álcool e drogas. As sessões foram conduzidas pela coordenadora, auxiliada pela bolsista do projeto. Todas as etapas da realização das sessões foram detalhadamente registradas no diário de campo para análise dos resultados.

\section{Resultados e Discussáo}

PDI - Aluna E.

Através das informações obtidas pelo PDI da aluna E. observa-se que a mesma encontra-se no $2^{\circ}$ ano do Ensino Médio e apresenta necessidades educacionais especiais, devido ao fato de possuir dificuldade de aprendizagem e limitações associadas às áreas de conduta adaptativa em aspectos da comunicação, independência na locomoção, habilidades sociais, desempenho na família e na comunidade. Ela começou a frequentar a sala de recursos multifuncionais quando estava no $8^{\circ}$ ano do Ensino Fundamental e continua desde então. Faz uso da comunicação oral e necessita de currículo adaptado para acessibilidade escolar.

E. faz parte de uma família simples e conturbada e reside em um bairro de periferia. Sua mãe também possui certo comprometimento intelectual e as condições do ambiente familiar não favorecem a aprendizagem escolar.

A aluna não tem outros problemas de saúde associados e não faz uso de medicamentos controlados.

Quanto ao desenvolvimento da aluna baseadas nas funções cognitivas, pôde-se perceber através do PDI que sua percepção espacial e temporal encontra-se afetada, bem como sua atenção, que precisa ser dirigida devido à dificuldade de concentração. Ela cumpre ordens e com 
assistência consegue realizar uma atividade sequencializada. Também apresentou comprometimento de memória auditiva, visual, verbal e númerica.

Em relação a sua linguagem também é muito deficitária, ela se expressa de forma simples por possuir um vocabulário pobre, lê com muita dificuldade e só escreve quando ditado, compreende razoavelmente, necessitando de muitos exemplos e facilitações para compreensão. $O$ raciocínio lógico de $E$. encontra-se totalmente prejudicado em aspectos de resolução de situações-problema, sequência lógica e problemas cotidianos. Compreende razoavelmente relações de igualdade e diferença, reconhecimento de absurdos e o mundo que a cerca.

No que diz respeito à sua função motora, não há problemas maiores, a não ser noção de lateralidade e orientação espaçotemporal. $\mathrm{Na}$ área pessoal/social apresenta-se equilibrada emocionalmente, interage bem, é cooperativa, reage bem à frustração e não demonstra medos ou isolamento social.

\section{PDI - Aluno G.}

Através das informações obtidas pelo PDI do aluna $G$. observa-se que o mesmo encontra-se no $2^{\circ}$ ano do Ensino Médio, na mesma sala da aluna E. e apresenta necessidades educacionais especiais. Em 2012 deixou de frequentar a sala de recursos multifuncionais da outra escola que estudava, devido ao seu avanço em todos os âmbitos do processo educacional, essa decisão foi tomada juntamente com os pais e o aluno recebeu as adaptações curriculares necessárias. Entretanto, 0 aluno necessita frequentar a sala de recursos multifuncionais da escola em que se encontra para receber o reforço necessário para acompanhar a turma, 0 mesmo mostra-se resistente e participa apenas de algumas atividades na sala de recursos. Faz uso da comunicação oral e necessita de currículo adaptado para acessibilidade escolar.

G. faz parte de uma família simples e conturbada e reside em um bairro de periferia. Sua mãe também possui certo comprometimento intelectual e as condições do ambiente familiar não favorecem a aprendizagem escolar.

O aluno não tem outros problemas de saúde associados e não faz uso de medicamentos controlados.

Quanto ao desenvolvimento do aluno baseadas nas funções cognitivas, pôde-se perceber através do PDI que sua percepção encontra-se adequada, bem como sua atenção. Ele cumpre ordens, concentra-se nas atividades, mantém 0 foco e identifica peesonagens. Sua memória é boa, exceto a númerica.

Em relação a sua linguagem, apresenta-se razoável, ela se expressa bem, lê e escreve corretamente, possuindo apenas dificuldades na compreensão, necessitando de exemplos e facilitações o entendimento.

$O$ raciocínio lógico de $E$. encontra-se limitado em aspectos de conclusões lógicas, resolução de situações-problema, sequência lógica, problemas cotidianos e o mundo que o cerca. Compreende bem relações de igualdade e diferença, reconhecimento de absurdos e compreensão de ordens.

No que diz respeito à sua função motora, não existem problemas, apenas encontrase afetada a orientação espacial. $\mathrm{Na}$ área pessoal/social apresenta-se equilibrado emocionalmente, interage bem, é cooperativo, reage bem à frustração e não demonstra medos ou isolamento social.

\section{Âmbito Escolar}

A escola tem uma cultura inclusiva e recepciona alunos com deficiência. Funciona em período integral e possui interação com as famílias dos alunos.

Oferece currículo adaptado ao alunos com necessidades educacionais especiais e possui a sala de recursos multifuncionais.

De todas as dificuldades encontradas em ambos os alunos, percebe-se que as principais delas são associadas às funções cognitivas. Dessa forma, devido ao tempo proposto das intervenções e da semelhanças de déficits, foram escolhidos aspectos de atenção, memória, linguagem, raciocínio lógico e percepção para serem trabalhados de forma a contemplar os dois participantes da pesquisa. 
Segundo Ballone (2003) hoje, apesar da pressão social negativa, as crianças com deficiência intelectual, podem contar com recursos educacionais e com uma equipe interprofissional que as orientam, chegando à vida adulta de maneira relativamente independente, inclusive na área de trabalho, como exemplo de uma história positiva a fim de corroborar contra as pressões sociais que recaem nas pessoas com deficiência intelectual.

Nessa perspectiva, os terapeutas ocupacionais intervêm por meio das ocupações em pessoas afetadas por processos desadaptativos, de diversos tipos, que ameaçam sua saúde, como: enfermidades, traumas ou condições sociais que afetaram sua saúde biológica ou psicológica. Portanto a Terapia Ocupacional é um meio de reorganizar o comportamento ocupacional das pessoas para alcançar os máximos níveis possíveis de saúde e bem estar. (ONEL, COFRÉ e ROJAS, 2001)

O atendimento terapêutico ocupacional com o uso da TAA permite a construção de um novo cotidiano, por meio das oportunidades oferecidas, pois no processo de intervenção, estreitam-se laços de confiança, amizade e afetividade. Por meio desse vínculo, pode-se trabalhar no sentido de aumentar a auto-estima, as relações interpessoais, a capacidade adaptativa e o desenvolvimento de habilidades, facilitando gradativamente que a pessoa alcance maior independência. Referem-se ainda a perceber aumento do pensamento crítico, estimulação dos processos cognitivos, com um olhar mais amplo e atento da realidade que a rodeia. (CARVALHO e SCATOLINI, 2003)

\section{Atendimentos - Aluna E.}

Os dados relativos aos atendimentos mediados pela Terapia Assistida por Cães revelaram que seu uso é muito benéfico, uma vez que promove motivação ao assistido e aumenta o vínculo entre 0 terapeuta e o paciente.

$\mathrm{O}$ animal como agente facilitador para a terapia, pode ser considerado uma ponte de comunicação entre 0 terapeuta e 0 paciente/usuário, além do que dá ressonância as sentimentos e favorece sua exteriorização. $O$ animal é um catalisador, ele atrai, modifica e faz a conexão entre dois elementos: a pessoa e o profissional (DOTTI, 2005, p.34).

Através dos atendimentos, pôde-se perceber dificuldades de raciocínio, concentração e expressão verbal nas atividades. Foram necessários muitos estímulos para a realização das mesmas, que eram sempre auxiliadas e direcionadas para serem finalizadas adequadamente.

Os atendimentos com E. eram sempre motivados pela presença do cão e ela respondia bem às atividades e relatou gostar bastante, embora possuísse inúmeras dificuldades relacionadas à escrita, leitura, memória e atenção. E. é uma adolescente interessada, comunicativa e participativa.

Durante as sessões, E. fazia carinho no cão, dava água e no início e no término do atendimento passeava com ele pela escola. $\mathrm{Em}$ todas as sessões, as atividades anteriores eram relembradas e às vezes até repetidas, pois segundo Faria (1998) os esquemas cognitivos, os quais conduzem ao desenvolvimento da inteligência, têm necessidade de serem repetidos, podendo vivenciar a mesma atividade por várias vezes.

As atividades oferecidas nas dez sessões consistiram em situações-problemas envolvendo manuseio de dinheiro, agenda informativa sobre o cão, organizar os horários no relógio de ponteiro, calendários, mapas, história em quadrinhos, confecção de objetos para o cão, sessão de autocuidado, atividades impressas de associar, diferenciar e completar e jogos.

Observou-se desorganização de pensamento tanto nas atividades vivenciadas, quanto na compreensão e sequenciação das atividades propostas. No caso de E., motivada pela presença do cão, percebeu-se melhora na expressão verbal e no pensamento através da solicitação do repasse das atividades realizadas no dia e nos outros atendimentos. Os dados colhidos são significativos, pois demonstram a utilização do cão como 
modelo e agente favorecedor de situações de aprendizagem.

Os atendimentos que envolveram jogos de mímica foram mais empolgantes para a participante $e$ as observações feitas sugerem que o cão, além de estimular capacidades cognitivas, através de estímulos sensoriais, motores e afetivos, tem forte função lúdica no processo terapêutico, capaz de dar respostas imediatas e interativas.

O lúdico, ao contribuir para melhorar a relação entre o terapeuta e 0 atendido, favorece essa comunicação, como ferramenta válida inclusive para a aderência à aprendizagem (OLIVEIRA, 2007). Brincadeiras e jogos têm o poder de envolver e motivar, e assim resgatar processos mentais de forma saudável, inserindo no contexto vital uma dinâmica viva, espontânea e atraente que convida a participar, criar e arriscar-se na tentativa de novos caminhos (FRIEDMANN, 1996; OLIVEIRA e MÁXIMO, 2005).

\section{Atendimentos - Aluno G.}

G. realizou as atividades sem a presença do cão e foi mais difícil despertar sua atenção, foi necessário descobrir seus interesses e buscar integrá-los aos atendimentos para que houvesse motivação do aluno.

Diferente de E., G. sabia ler e escrever muito bem, interagia melhor e mantinha-se atento por mais tempo na atividade.

As atividades oferecidas nas dez sessões consistiram em situações-problemas envolvendo manuseio de dinheiro, organizar os horários no relógio de ponteiro, calendários, fita métrica, mapas, história em quadrinhos, atividades impressas de associar, diferenciar e completar e jogos.

As atividades também eram relembradas e repetidas para fixação.

O trabalho realizado com $\mathrm{G}$. não tinha nada de muito atrativo, o que tornou os atendimentos mecanizados.

O aluno com deficiência intelectual necessita aprender a ser e a viver, necessita ser capaz de valorizar a visão positiva de si mesmo, estimular seu desejo e confiança.
É necessário ter criatividade ao propor atividades que visem atender aos objetivos educacionais indicados para a educação do deficiente intelectual e persistência em relação aos mesmos, pois cada ganho, por mínimo que seja, pode ser muito grande para um adolescente com DI.

Segundo Mantoan (1989), ao considerar o aluno com deficiência intelectual a partir do que ele é capaz de ser, de fazer, de enfrentar, de assumir como pessoa, revelam-se a todos nós e a ele próprio possibilidades que se escondiam, que não Ihe eram creditadas, por falta de oportunidades de emergirem espontaneamente. Os pais, professores, especialistas e a sociedade em geral terão clarificados os quadros de deficiência intelectual, na medida em que derem um crédito de confiança para competência e o desempenho dos deficientes, no dia-a-dia da casa, nos estudos, no esporte, no lazer, nas atividades culturais e religiosas. As crianças com D.I. necessitam de credibilidade, necessitam que acreditemos em seu aprendizado. Quando estimuladas e incentivadas, as crianças com D.I., nos mostram aprendizagens e desenvolvimentos que nos surpreendem.

\section{Conclusões}

A Terapia Assitida por Cães demonstra ao longo dos tempos ser uma forma de abordagem muito útil e eficaz para a melhora do indivíduo com diferentes patologias e têm possibilitado as pessoas diversas mudanças que estão implicadas no seu desenvolvimento biopsicossocial.

Muitas vezes, as pessoas com deficiência intelectual possuem dificuldades em áreas que são primordiais para realização das atividades de vida diária, dessa forma, cabe à Terapia Ocupacional buscar meios de estimulá-las para alcançar o máximo de independência e autonomia na vida do indivíduo.

Infelizmente, crianças e adolescente com DI são pouco estimulados, de forma que o desenvolvimento se torna deficitário, impedindo que demonstrem de forma efetiva suas potencialidades. 
Um animal como facilitador pode promover inúmeras mudanças na vida de indivíduos com DI.

Sugere-se a continuação de pesquisas nessa linha, estudando a intervenção de animais como facilitadores junto à crianças e adolescentes com deficiência intelectual.
Conpañia: implicaciones en la salud humana y relación con la terapia ocupacional. Revista Chilena de Terapia Ocupacional. n.1, p. 26-30, 2001.

POKER, R. B.; MARTINS, S. E. S. O. ; OLIVEIRA, A.A.S; MILANEZ, S. G. C. ; GIROTO, C. R. M. . Plano de Desenvolvimento Individual. $1^{\mathrm{a}}$ ed. São Paulo: Oficina Universitária/Cultura Acadêmica, 2013. 227p
BALlONE, G. J. (2003). Psiquiatria e Patologias Básicas. São Paulo: Vetor.

BAUN, M. M.; OETTING, K.; GERGSTROM, N. Health benefits of companion animals in relation to the physiologic indices of relaxation. Holistic Nursing Practice, v. 5, p. 16-23, 1991.

CAETANO, E. As contribuições da TAA - Terapia Assistida por Animais à psicologia. Trabalho de Conclusão de Curso. Criciúma - Sc. 2010

CAPOTE, P. S. O.; COSTA, M. P. R. Terapia Assistida por Animais: aplicação no desenvolvimento psicomotor da criança com deficiência intelectual. São Carlos: Edufscar, 2011.

CARVAlHO, A. F. C. T., SCATOLINI, H. M. N. Terapia Ocupacional na Complexidade do Sujeito. Rio de Janeiro Ed. Independente, 2003. p. 47-48

DOTTI, J. Terapia e Animais. $1^{\text {a }}$ ed. São Paulo: Noética, 2005.

FARIA, N. R. B. (1998). Buscando os limites do dado na aquisição da linguagem. Disponível em:

$<$ http://www.nce.ufrj.br/ginape/publicacoes/trabalhos/t 200 2/t_2002_renato_aposo_e_francine_vaz/psicolinguistica.htm $>$ Acesso em 15/07/2015

FERREIRA, J. M. A Cinoterapia na APAE/SG: um estudo orientado pela teoria bioecológica do desenvolvimento humano. Conhecimento \& Diversidade, Niterói, n.7, p. 98-108, jan./jun. 2012.

FLÔRES, L. N. Os benefícios da interação homem animal e o papel do médico veterinário. Porto alegre, RS. 2009. Monografia (Especialização em clínica médica de pequenos animais) - Universidade Federal Rural do Semi-Arido.

LEAL, G.; NATALIE, K. Afeto que cura. Revista Mente e Cérebro - 2007.

MANTOAN M. T. E., Compreendendo a deficiência mental: novos caminhos educacionais. Scipione, 1989.

OLIVEIRA, V. B.. O Brincar no Hospital e a Aderência ao Tratamento. In: M. M. M. Siqueira, S. N. Jesus \& V. B. Oliveira (Orgs.). Psicologia da Saúde: Teoria e Pesquisa. São Bernardo do Campo: UMESP, 2007

OLIVEIRA, V. B. E Máximo, I. M. N. S.. Reabilitação lúdica da imagem corporal. Boletim da Academia Paulista de Psicologia, v. 25, n. 1, p. 37-48, 2005.

ONEL, C. A., COFRÉ, M. A. P. e ROJAS, A., V. Impacto de La Interacción de Personas con Animales de 